\title{
FORMAÇÃO E ATUAÇÃO DO TUTOR COMO ORIENTADOR DE PESQUISA NA EDUCAÇÃO ON-LINE'
}

\author{
THE TRAINNING AND PRACTICE OF TUTORS AS RESEARCH SUPERVISORS IN \\ ONLINE EDUCATION
}

\section{FORMACIÓN Y SUPERVISIÓN DE TUTORES COMO MENTORES DE INVESTIGACIONES IN EDUCACIÓN EN LÍNEA}

Marcelo Giordan'2, Luciana Massi ${ }^{3}$

RESUMO

Neste artigo, caracterizamos o trabalho de formação e acompanhamento de tutores que atuaram como orientadores de Trabalhos de Conclusão de Curso no Curso de Especialização em Ensino de Ciências do programa Rede São Paulo de Formação Docente oferecido pela Universidade de São Paulo. Adotamos o modelo dos sistemas de atividade para analisar a atividade de orientação e, a partir das respostas dos tutores a um questionário, identificamos aspectos centrais para esta análise: a autonomia para orientação, as regras do sistemas de atividades e a comunidade. Com base nessa perspectiva teórica, vários elementos indicam a criação efetiva de uma comunidade de prática que teve papel fundamental na formação do orientador e para a reestruturação de atividades fundamentais da orientação, como a escrita e a comunicação, no contexto educação on-line.

PALAVRAS-CHAVE: Papel do orientador. Tutor. Educação on-line. Formação continuada, Sistemas de Atividades.

\begin{abstract}
In this article, we outline and discuss the training and practices of tutors who worked as supervisors on term papers in a specialization course on science education offered by the Sao Paulo Network of Teacher Education at Sao Paulo University. Based on the activity systems model we analyse the supervision practices together with tutor's answers to a questionnaire and identify main aspects to this analysis: 1) the supervision's autonomy, 2) the rules of the activity systems and 3 ) the community. According to this theoretical perspective, many elements point to the effective creation of a community of practice, which had a fundamental role in supervisor's education, and to the restructuring of basal supervising activities, such as writing and communication, in a context of online educational.
\end{abstract}

KEYWORDS: Supervisor's Role. Tutor. Online Education. In-service training. Activity Systems.

\footnotetext{
${ }^{1}$ Uma versão preliminar e resumida deste texto foi publicada no Simpósio Internacional de Educação a Distância e Encontro de Pesquisadores em Educação a Distância ocorrido na Universidade Federal de São Carlos em 2014. ${ }^{2}$ Doutor em Ciências - Universidade Estadual de Campinas (UNICAMP) - São Paulo, SP - Brasil. Livre Docente Universidade de São Paulo (USP), São Paulo, SP - Brasil. Professor da Faculdade de Educação da Universidade de São Paulo (USP) - São Paulo, SP - Brasil. E-mail: giordan@usp.br

${ }^{3}$ Doutora em Ensino de Ciências - Universidade de São Paulo (USP) - São Paulo, SP - Brasil. Professora da Universidade Estadual Paulista (UNESP), Faculdade de Ciências e Letras - Araraquara, SP - Brasil. E-mail: lucianamassi@fclar.unesp.br
}

Submetido em: 30/06/2017 - Aceito em: 21/09/2017

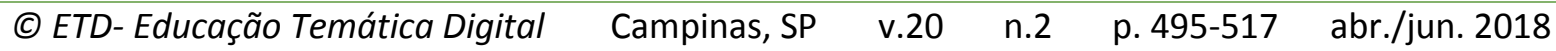




\section{RESUMEN}

En este articulo, se caracteriza el trabajo de formación y supervisión de tutores que actuaran como mentores de Trabajos de Conclusión de Curso no Curso de Especialização em Ensino de Ciências del programa Rede São Paulo de Formação Docente ofrecido por la Universidad de São Paulo. Hemos adoptado el modelo de sistemas de actividad para analizar la orientación de la actividad y, a partir de las respuestas de los tutores a un cuestionario, identificamos los aspectos clave de este análisis: autonomía para la orientación, las reglas de las actividades y la comunidad. Sobre la base de esta perspectiva teórica, existe evidencia de la creación efectiva de una comunidad de práctica que jugó un papel clave en la formación del mentor y para la reestructuración de las actividades clave de orientación, tales como la escritura y la comunicación en el contexto de la educación en línea.

PALAVRAS CLAVE: Rol del supervisor. Tutor. Educación en línea. Formación en servicio. Sistemas de actividad.

\section{INTRODUÇÃO}

A importância da pesquisa tem crescido fortemente nas universidades, imprimindo padrões de produtividade desafiadores para a comunidade científica. Nesse contexto adverso, o papel do orientador assume relevância ainda maior no desenvolvimento de uma pesquisa acadêmica ao influenciar diretamente na qualidade do trabalho do estudante e, eventualmente, até na sua decisão de concluir a pós-graduação e optar pela carreira acadêmica (MCCALLIN; NAYAR, 2012). Apesar dessa importância, a formação do orientador não é objeto de ações formativas de programas oficiais, objeto de pesquisa de nenhuma área específica e, geralmente, nem sequer objeto de discussão na universidade. Permanece à margem do âmbito político e investigativo uma questão que nos parece fundamental: como se formam e se desenvolvem os orientadores de pesquisa?

Essa problemática assume novos contornos no contexto dos cursos on-line, nos quais a produção de trabalhos de conclusão costuma ser frequente. Neles, o trabalho de orientação é específico, seja pelas formas de interações, seja pela assincronicidade e distância física. Além disso, as tarefas frequentemente atribuídas a um único docente passam a envolver uma comunidade com vários diferentes sujeitos (coordenação, professores, tutores, equipe técnica), levando-nos a questionar: como esses sujeitos se organizam, em relação às ferramentas e suportes e à comunidade, para a atividade de orientação dos trabalhos de pesquisa?

Essas questões são objeto de pesquisa deste trabalho, no qual caracterizamos a atuação de tutores em um ambiente virtual de aprendizagem como orientadores de Trabalhos de Conclusão de Curso (TCC) do Curso de Especialização em Ensino de Ciências da Rede São Paulo de Formação Docente oferecido pela Faculdade de Educação da Universidade de São Paulo (EEC-FEUSP-REDEFOR). Adotamos a Teoria Histórico Cultural da Atividade e o modelo de Sistemas de Atividade para analisar esses resultados, pois "o EEC-FEUSP-REDEFOR é um complexo sistema de atividades formado por diversos subsistemas que interagem entre si com o propósito de desenvolver o processo formativo do professor-cursista" (GIORDAN;

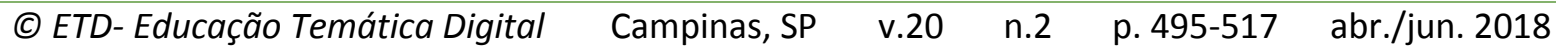


NERY, 2013, p. 269). Essa perspectiva teórica nos auxilia a analisar dois aspectos: 1) a formação do orientador dentro de uma comunidade de prática e 2) a reconfiguração que a modalidade de educação on-line traz para o trabalho de orientação.

Quanto ao primeiro aspecto observamos a inserção dos aprendizes nessa comunidade de prática de orientação, uma vez que "o domínio do conhecimento e da prática exige dos recém-chegados que se encaminhem para a plena participação nas práticas socioculturais de uma comunidade" (LAVE; WENGER, 1991, p. $29^{4}$ apud DANIELS, 2003, p. 96). Nesse contexto, a aprendizagem adquire novos sentidos, já que "as intenções de uma pessoa de aprender são engajadas, e o significado da aprendizagem é configurado pelo processo de tornar-se um participante pleno de uma prática sociocultural" (LAVE; WENGER, 1991, p. 29 apud DANIELS, 2003, p. 96).

Quanto ao segundo aspecto, percebemos que essa reconfiguração - a orientação no ensino on-line - toca na questão dos instrumentos de mediação, que é caro à teoria da atividade. Segundo Daniels (2003, p. 124)

quando um sistema de atividade adota um novo elemento de fora (por exemplo um nova tecnologia ou um novo objeto), ele causa uma contradição secundária agravada, em que algum antigo elemento (por exemplo as regras ou a divisão de trabalho) colide com o novo.

No ensino on-line, novos instrumentos para mediar a interação sujeito-conhecimento e sujeito-sujeito estão à disposição da comunidade, como por exemplo, as ferramentas de comunicação e informação digitais, que têm propriedades qualitativamente distintas e podem, portanto, suscitar alterações na forma de organização da atividade.

O modelo de sistema de atividades tem sido empregado em diversas pesquisas (ENGESTRÖM; MIETTINEN; PUNAMÄKI, 1999; SANNINO; DANIELS; GUTIÉRREZ, 2009), sobretudo quando envolvem a participação de diferentes agentes que compartilham meios mediacionais e um objeto comum que constitui o motivo da atividade. Engeström (1987/2014) propôs uma expansão do triângulo da mediação de Vigotski que inclui as regras e a divisão de trabalho em uma comunidade da qual fazem parte os agentes de um sistema de atividade. Esse modelo é particularmente útil para interpretar processos complexos relacionados aos ciclos expansivos da aprendizagem, movidos pela dinâmica de contradições inerentes às formas de produção humana, tal qual encontramos nos ambientes virtuais de aprendizagem, exatamente por considerarmos a aprendizagem e o desenvolvimento humano

\footnotetext{
${ }^{4}$ LAVE, J., WENGER, E. (1991). Situated learning: Legitimate Peripheral Participation, Cambridge, Cambridge University Press.
} 
como processos mediados por instrumentos de caráter material e simbólico.

A formação e o papel do orientador na literatura internacional e nacional

Apesar de ter pouca representatividade quantitativa, encontramos uma ampla e consistente literatura internacional sobre o papel do orientador, o que seria um bom e um mau modelo de orientação, quais seriam as características esperadas de um orientador, como deveria ser a relação entre orientador e orientando. A maioria dos trabalhos analisou essas questões através de questionários aplicados a orientandos de doutorado (ZHAO, 2005) ou orientadores (STEPHENS, 2014) ou apresentou propostas formativas (focadas em narrativas, grupos focais e estudos de casos) voltadas, principalmente, para os orientadores inexperientes (MANATHUNGA et al., 2010; SWEITZER, 2009; MCCORMACK, 2009). Dentre essas discussões selecionamos as mais representativas, principalmente revisões da literatura (LEDER, 1995; BUTTERY et al., 2005; MCCALLIN; NAYAR, 2012), e que estivessem associadas à nossa questão de pesquisa. Apresentamos a seguir essas contribuições.

Um primeiro questionamento que parece óbvio, mas que não tem respostas simples é sobre o papel do orientador. Sabemos que não há clareza sobre esse tema (LEDER, 1995; BUTTERY et al., 2005): um orientador é um professor mais avançado, um debatedor crítico, um tutor? Uma complicada consequência deste problema é a existência de diferentes modelos de orientação sem parâmetros mínimos de atuação. Com base em levantamento bibliográfico Leder (1995) propõe que a orientação envolve os seguintes papéis: oferecer orientação quanto ao tema e programa da pesquisa; oferecer orientação quanto aos aspectos éticos envolvidos no projeto; fornecer informações sobre o tamanho, âmbito e padrão de uma pesquisa considerando a especificidade do tipo de formação e da área; facilitar o acesso e, se necessário, o financiamento para os recursos essenciais da pesquisa; dar suporte pessoal, financeiro (bolsa), oportunidades de trabalho e referências; encorajar ao longo do desenvolvimento da pesquisa, dar retornos construtivos, positivos e críticos; usar o relatório como indicativo do progresso da pesquisa; encorajar a participação em apresentações em conferências e usar essas ocasiões para introduzir o orientando aos colegas da área; ser honesto quanto à qualidade do trabalho e à perspectiva de conclusão; ser criterioso quanto à seleção dos examinadores.

Além de diferentes modelos de orientação, decorrentes da ausência de clareza quanto ao papel do orientador, muitos autores apontam para a existência de diferentes estilos de orientação. Eles favoreceriam uma melhor ou pior adaptação entre orientador e orientando e seriam uma justificativa, apoiada na literatura, para universidades abolirem o formato de orientação única, substituindo-o por um grupo de orientadores para um mesmo orientando (BUTTERY et al., 2005). A partir de um levantamento bibliográfico, Buttery e colaboradores

$\begin{array}{llllll}\text { (C) ETD- Educação Temática Digital } & \text { Campinas, SP } & \text { v.20 } & \text { n.2 } & \text { p. 495-517 } & \text { abr./jun. } 2018\end{array}$ 
(2005) elencaram quatro estilos de orientação que seriam indicadores de eficácia para o orientador:

1. Estilo de orientação refletido no nível de direcionamento; tempos regulares de orientação com o estudante; liberdade para que o aluno desenvolva suas ideias; flexibilidade na definição do projeto de pesquisa; promoção de interação com outros orientandos; oportunidades de participação em conferências e publicações.

2. Competência do orientador quanto ao conteúdo científico da pesquisa; familiaridade com a literatura da área; experiência na área de pesquisa; contatos internacionais com outros pesquisadores do mesmo tema.

3. Características de orientação marcadas por acessibilidade e amizade; dá apoio e motivação; é aberto ao reconhecimento do erro; é organizado ao mesmo tempo em que encoraja e estimula o entusiasmo com a pesquisa; não é obcecado com produtividade.

4. Habilidade do orientador associada à criatividade e flexibilidade de ideias; excelência intelectual; envolvimento consistente com a pesquisa; bons níveis de produtividade; boa captação de recursos externos para a pesquisa.

Nesse mesmo estudo, os autores apontam os principais problemas associados a orientação na pós-graduação: falta de experiência, compromisso e tempo do orientador; problemas emocionais e psicológicos associados ao isolamento e insegurança do estudante quanto à sua capacidade de realizar a pesquisa; falta de compreensão e comunicação entre o orientador e o orientando; falta de conhecimento, habilidade, treinamento ou experiência na metodologia de pesquisa (BUTTERY et al., 2005).

A revisão de McCallin e Nayar (2012) aborda especificamente a orientação de pesquisas de pós-graduação na Nova Zelândia a partir de trabalhos publicados sobre o tema entre 2000-2010, focando em uma análise crítica das perspectivas mais atuais e recorrentes presentes nessa literatura. $O$ artigo enfatiza as mudanças em relação ao financiamento das pesquisas, cada vez mais direcionadas para o mercado e a inserção profissional dos pósgraduandos, como motivadoras de alterações 1) no contexto de pesquisa, 2) nas questões de competência, 3) na pedagogia da orientação e 4) nos modelos de orientação. Quanto ao contexto, os autores destacam a contradição entre, por um lado, uma preocupação em ampliar a taxa de conclusão, respeitando e reduzindo o tempo de realização das pesquisas, e, por outro, as condições de trabalho dos orientadores que precisam receber cada vez mais estudantes, enfrentar uma competição por recursos cada vez mais acirrada, se preocupar com a internacionalização das pesquisas e com a orientação de estudantes internacionais. Quanto às competências envolvidas na orientação, McCallin e Nayar (2012) indicam a importância de uma formação específica para que o orientador seja capaz de orientar uma

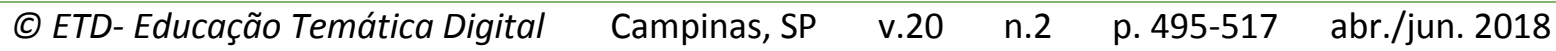


pesquisa de qualidade dentro dos prazos previstos para sua realização. Essa competência depende de uma "pedagogia da orientação", surgida na última década como forma de reconhecer a importância do papel do orientador como promotor de um tipo específico de "ensino" com suas próprias especificidades e funções, além das questões metodológicas (já reconhecidas).

Atualmente a orientação se desenvolve em função das preferências do orientador em adotar um modelo de orientação do tipo "hands-off, em que o estudante organiza sua própria pesquisa, ou "hands-on", que é mais estruturada pelo orientador e tende a promover a conclusão do estudo em menor tempo. McCallin e Nayar (2012) reconhecem que existem diferentes concepções do que seria essa "pedagogia da orientação". Quanto aos modelos de orientação eles apresentam três formatos gerais: modelo tradicional, que envolve uma relação diádica entre orientador e orientando; a orientação em grupo, envolvendo a relação entre orientador e orientando e dos orientandos entre si; e o modelo misto que incorpora novas tecnologias de comunicação ao modelos anteriores. Por fim, os autores discutem duas estratégias de melhoria das práticas de orientação: 1) desenvolvimento de competências dos orientadores para pesquisa em um contexto de mudança e 2) implementação de programas formativos para estudantes que complementem a atividade de orientação sobre revisão de literatura, ética em pesquisa, etc.

A literatura nacional é muito mais escassa, descritiva e dispersa, tanto em relação ao tema (com enfoque em atividades ou contextos particulares de orientação) e publicada majoritariamente em eventos e livros. Destacamos aqui alguns artigos que contribuem para a discussão. Concordando em parte com os dados anteriores sobre a importância do orientador, no Brasil encontramos referência à evasão e à depressão dos pós-graduandos associada a problemas na relação orientador-orientando (ALVES; ESPINDOLA; BIANCHETTI, 2012). Outra pesquisa nacional, publicada nesta revista, focada no contexto de formação do professor-reflexivo envolvido na produção de TCC do curso de Pedagogia, concorda com a literatura internacional (RAUSCH; SADALLA, 2008). Segundo as autoras, o orientador é muito importante na promoção da reflexividade docente durante a pesquisa.

Destacam-se nessa literatura nacional, as publicações de Lucídio Bianchetti, da Universidade Federal de Santa Catarina, e de seus colaboradores sobre o tema. Partindo de dados coletados no projeto de pesquisa "Política Educacional: Orientação/escrita de dissertações e teses em questão", na qual entrevistou 74 orientadores brasileiros e 14 europeus sobre seu trabalho, Bianchetti defende que o modelo de pós-graduação brasileiro sofreu uma profunda mudança. Inicialmente as políticas da Coordenação de Aperfeiçoamento de Pessoal de Ensino Superior (CAPES) tinham como objetivo a formação

$\begin{array}{llllll}\text { (C) ETD-Educação Temática Digital } & \text { Campinas, SP } & \text { v.20 } & \text { n.2 } & \text { p. 495-517 } & \text { abr./jun. } 2018\end{array}$ 
de quadros para as universidades. A partir da década de 90 , influenciada pelo modelo norteamericano de pesquisa, a CAPES passa a visar a formação do pesquisador numa sistemática de avaliação e financiamento (BIANCHETTI; QUARTIERO, 2010; ALVES; ESPINDOLA; BIANCHETTI, 2012). Esse modelo de produção do conhecimento também influenciou a Europa, tanto na graduação, através do Processo de Bolonha, quanto nas exigências para os professores-pesquisadores-orientadores, estimulando a redução dos tempos de formação e trabalhos coletivos de pesquisa e orientação, já apontados em nosso levantamento internacional (BIANCHETTI; QUARTIERO, 2010).

No contexto nacional, estudos focados nos processos de escrita envolvidos na orientação parecem receber atenção proporcionalmente significativa. Araújo e Oliveira (2014, p. 95) a entendem como a essência da pesquisa: "muito do que acontece durante estes processos de tornar-se mestre ou doutor relaciona-se com a escrita e com os modos de escrever" e "tem a ver com o tempo para a escrita e a duração do escrever", constituído com os orientadores. Os autores estimam que metade do trabalho de orientação se refere a "questões de estilo, clareza e forma em relação ao processo de escrita/pesquisa" (CASTRO, $2006^{5}$ apud ARAÚJO; OLIVEIRA, 2014, p. 101). Riolfi e Andrade (2009) acompanharam o processo de escrita de duas orientandas de mestrado durante 36 meses e concluíram que o orientador cumpriu cinco funções diferentes: 1) diretor de trabalhos, 2) leitor, 3) coautor, 4) revisor e 5) agente do real. Assim as autoras ratificam "a alegada dificuldade para orientar um trabalho acadêmico" (RIOLFI; ANDRADE, 2009, p. 99). Pesquisas internacionais sugerem que deveria haver uma pessoa específica para essa orientação ao invés do orientador acumular essa função (BUTTERY et al., 2005).

Quanto ao trabalho de orientação em articulação com as tecnologias de informação e comunicação (TIC), Alves, Espindola e Bianchetti (2012) entendem que essas ferramentas e o novo modelo de pós-graduação provocaram mudanças no papel dos orientadores que vivenciaram um aumento significativo na sua carga de trabalho e passaram a interferir mais nas pesquisas dos orientandos visando o cumprimento dos estreitos prazos da pósgraduação. Nesse sentido, o trabalho de Buttery e colaboradores (2005) também discute sobre as potencialidades da comunicação eletrônica para o trabalho de orientação através de grupos de discussão entre os orientandos, cursos de metodologia de pesquisa online, orientação online dispensando a presença física e discussão de modelos de orientação para os orientadores.

\footnotetext{
${ }^{5}$ CASTRO, C. M. (2006), Memórias de um orientador de tese: um autor rêle sua obra depois de um quarto de século, in BIANCHETTI, L. \& MACHADO, A. M. N. A bússola do escrever: Desafios e estratégias na orientação e escrita de teses e dissertações, (2a edição - pp. 109-134), São Paulo: Florianópolis, Cortez: Editora da UFSC.
}

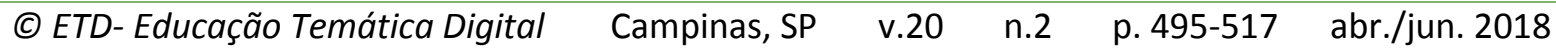


Diante dessa breve revisão bibliográfica é possível encontrar elementos que apontam para a caracterização do trabalho de orientação, mas também perceber lacunas que as pesquisas deixam quanto à compreensão desse processo apoiada em referenciais teóricos que permitam analisar a ação do orientador de uma perspectiva mais ampla. Nesse sentido, visando contribuir para essas discussões, nossa pesquisa parte da perspectiva sociocultural para analisar 1) a formação do orientador dentro de uma comunidade de prática e 2) a reconfiguração que a modalidade de educação on-line traz para o trabalho de orientação.

\section{CONTEXTO DE PRODUÇÃO E METODOLOGIA DE COLETA DE DADOS}

O REDEFOR foi uma iniciativa da Secretaria de Educação do Estado de São Paulo (SEESP), em parceria com universidades públicas paulistas. A Universidade de São Paulo (USP), através da Faculdade de Educação ofereceu o curso de Especialização em Ensino de Ciências aos professores da rede (EEC-FEUSP-Redefor). O curso teve 4 módulos com 2 disciplinas de 45 horas em cada módulo e duração de 10 semanas, totalizando 40 semanas de estudos on-line no decorrer do curso de aproximadamente 14 meses. Cerca de 25 professores-cursistas foram acompanhados por um tutor, licenciado na área de ciências, cursando ou portador de título de pós-graduação. Grupos de 15 tutores eram supervisionados por um tutor de acompanhamento, integrante da equipe de coordenação que contava ainda com responsáveis por outras áreas do curso, incluindo os autores deste texto. Assim, o curso estava composto por vários Sistemas de Atividades (SA), envolvendo a aprendizagem on-line, a tutoria, o apoio técnico, a coordenação etc. (GIORDAN; NERY, 2013). O TCC envolvia diretamente o SA Orientação, que se organizou em diferentes etapas, níveis e agentes, ilustrados na Figura 1 e explicados em detalhes a seguir.

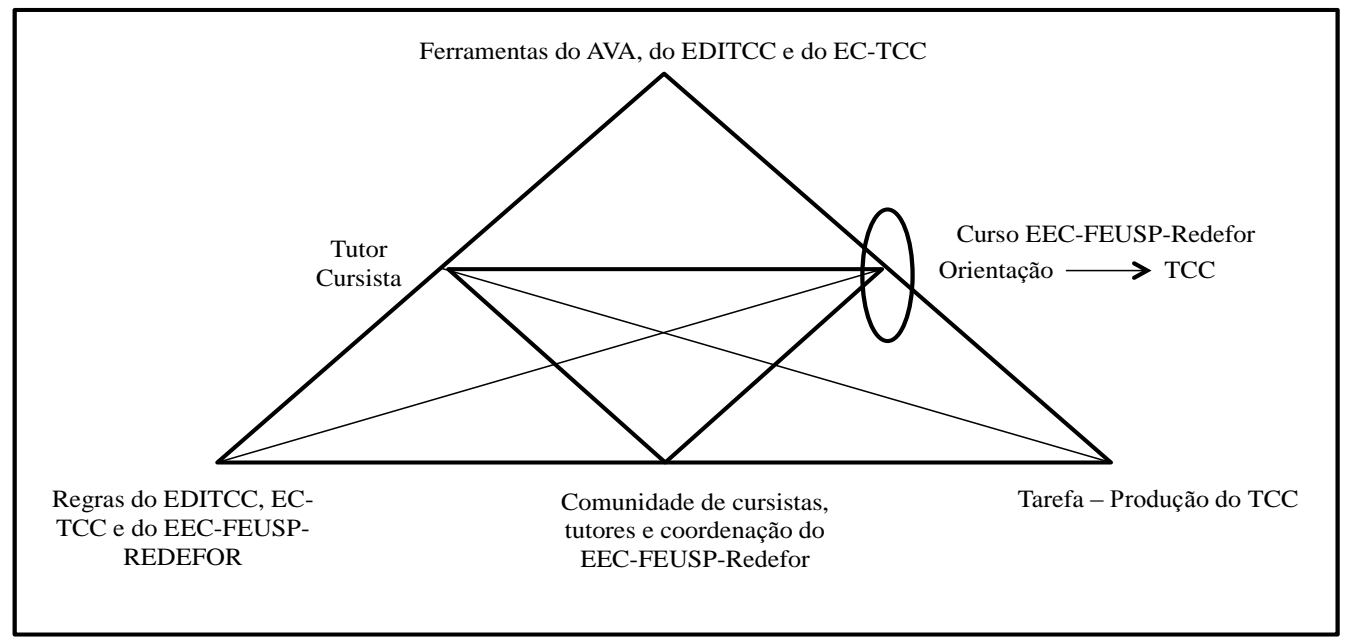

FIGURA 1 - Sistema de Atividade Orientação do TCC do EEC-FEUSP-Redefor. Fonte: os autores. 
Com base no princípio do compartilhamento de objetos entre sistemas de atividades (ENGESTRÖM, 2009), consideramos que os diferentes SA envolvidos no EC-FEUSP-Redefor interagem e formam redes, pois envolvem esferas distintas de produção humana e participação de grupos em diversas atividades de um programa mais amplo que as agrega, objetivando promover a formação continuada de professores de ciências (GIORDAN; NERY, 2014). Tal formação, segundo Engeström, deve levar a ciclos expansivos de aprendizagem e desenvolvimento, por meio da superação de contradições nos processos de internalização e externalização, que envolvem respectivamente o domínio de ferramentas e formas de ação, e a inovação individual que leva a outro modelo de atividade (ENGESTRÖM, 1999, p. 33-4).

Antecipamos o período de preparação para o TCC por meio do oferecimento aos cursistas do Estudo Dirigido de Iniciação ao TCC (EDITCC), com duração de 4 meses, equivalentes aos últimos meses de curso ${ }^{6}$. O EDITCC teve início em abril/2011, em agosto do mesmo ano todas as disciplinas do Curso de Especialização e o EDITCC terminaram e o cursista teve 2 meses para se dedicar exclusivamente à produção da pesquisa, entregue em novembro/2011. Ao longo do curso, foram produzidas sequências didáticas (SD), uma por módulo, sugeridas como objetos de investigação da pesquisa do TCC quanto ao ciclo de criação, organização, aplicação, avaliação e validação da SD, seguindo princípios teóricos e metodológicos do Modelo Topológico de Ensino (GIORDAN, 2008). O aproveitamento do trabalho de produção das SD refletiria o desenvolvimento dos cursistas ao longo do curso, de acordo com a concepção do TCC.

Para a organização do trabalho de orientação, dentre todos os tutores do curso, foram convidados a atuar como orientadores aqueles que possuíam mestrado na área de Ensino de Ciências ou áreas afins. Os grupos foram formados pelos alunos que já haviam sido orientados pelo tutor durante o oferecimento das disciplinas, sendo distribuídos em média 10 cursistas por tutor. Nesse sentido, o tutor também teria melhores condições de orientação por já ter acompanhado e avaliado a produção das SD. Para desenvolver o trabalho de orientação, foi criado um ambiente virtual específico para mediar as trocas entre orientador e cursista, chamado Ensino de Ciências - Trabalho de Conclusão de Curso (EC-TCC). Nesse ambiente, os alunos deveriam produzir quatro documentos referentes ao TCC: um projeto de pesquisa, duas versões preliminares e parciais do TCC e uma versão final completa. Resumidamente, esse ambiente virtual continha uma apresentação da proposta de pesquisa, fóruns de notícias e discussões, uma ferramenta de mensagens denominada "Diálogos sobre a Pesquisa", além de disponibilizar um modelo de projeto de pesquisa e de TCC com regras gerais para produção e apresentação desses textos. Na aba orientação do ambiente virtual, os cursistas tiveram

\footnotetext{
${ }^{6}$ Essa experiência foi descrita e avaliada em outra publicação (MASSI; GIORDAN, 2014).
}

$\begin{array}{llllll}\text { (C) ETD- Educação Temática Digital } & \text { Campinas, SP } & \text { v.20 } & \text { n.2 } & \text { p. 495-517 } & \text { abr./jun. } 2018\end{array}$


acesso a todo o conteúdo do EDITCC e ao calendário de trabalho. Um conjunto de artigos de referência sobre planejamento, aplicação e análise de sequências didáticas foi disponibilizado para servir de referência e fonte de citação. Também foi elaborada uma enquete para os cursistas contendo 44 itens em escala likert de 5 níveis e uma questão dissertativa, todos sobre aspectos da orientação, elaboração e cada uma das fases do processo, que não será analisada neste artigo.

Fundamentalmente, o SA Orientação, previamente apresentado na Figura 1, descreve e interpreta o processo de elaboração do TCC, cujo objeto central é a orientação que envolve a interação entre tutor e cursista para produzir e apresentar um texto na forma de artigo científico que consiste no trabalho de de conclusão do curso de especialização. Portanto, a orientação e a necessidade de conclusão do curso, quando articuladas, se materializam na forma de um resultado, o próprio texto de TCC. Nesse processo, as regras de orientação decorrem do estudo dirigido (EDITCC), que sugerem diretrizes para tutor e cursista de acordo com as fases de elaboração e desenvolvimento de um projeto de pesquisa pautado na construção de sequências didáticas. Além delas, regras gerais relativas ao curso de especialização, especialmente à sua fase final, também medeiam a relação entre tutoresorientadores, cursistas e a coordenação geral. No que diz respeito à divisão de trabalho, devese considerar não apenas aspectos da orientação em si, como direcionamento, devolutiva e crítica, mas também a produção do texto pelo cursista em cada uma de suas fases.

A disciplina EC-TCC como ferramenta para atuação dos tutores-orientadores foi apresentada pela coordenação em um momento formativo para que os tutores atuassem como orientadores dos TCC. Apesar de ter sido realizada em um único dia, foram discutidos vários aspectos da formação dos orientadores, considerando as contribuições da literatura. Inicialmente, apresentamos aos tutores uma contextualização das pesquisas sobre SD na área de Educação em Ciências. Em seguida, apresentamos um panorama sobre as pesquisas em ensino de ciências envolvendo a produção, aplicação e avaliação de SD (GIORDAN; GUIMARÃES; MASSI, 2011). De acordo com a competência do orientador quanto ao conteúdo científico da pesquisa, destacada por Buttery e colaboradores (2005), a proposta dessa apresentação era subsidiar teoricamente os orientadores quanto ao campo de estudos e o estado da arte das pesquisas favorecendo um melhor trabalho de orientação junto aos orientandos.

Após essa apresentação e contextualização inicial, passamos a uma discussão coletiva sobre as expectativas da coordenação e dos tutores quanto ao trabalho de orientação, considerando os seguintes temas e questões: Autonomia X Direcionamento - Como preservar a autonomia do orientador e do orientando, essenciais para a reflexão e pesquisa,

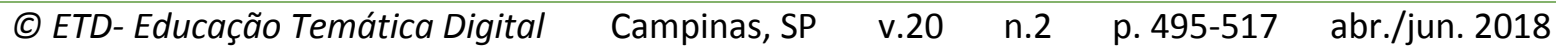


diante do pouco tempo disponível e da falta de experiência de ambos?; Tema de pesquisa Quais argumentos podemos usar em favor do uso da SD como tema de pesquisa para os cursistas? Qual grau de interferência o orientador poderá ter na pesquisa do cursista? Por exemplo, quanto à escolha do tema de pesquisa?; Sequência Didática - Como os cursistas conseguirão sair da lógica de um material que até então tinha um caráter de intervenção, as SD, para uma lógica de pesquisa?; Metodologia de pesquisa - Como justificar a opção pela pesquisa qualitativa?; Correção do Projeto e do TCC - Como iremos conduzir a correção de alguns parâmetros, como por exemplo, será que teremos que ser muito "enérgicos" se a metodologia não atender de forma completa aos objetivos, ou se a discussão não estiver bem relacionada com os resultados obtidos?

Essas questões envolviam a particularidade do trabalho de orientação em ambientes virtuais, cuja principal forma de mediação é a escrita, e no EC-FEUSP-Redefor, no qual a coordenação e os tutores dividiam essa tarefa. Nesse contexto, fica evidente a multivocalidade como um dos cinco princípios dos sistemas de atividades, pois "um sistema de atividades é sempre uma comunidade de múltiplos pontos de vista, tradições e interesses" (GIORDAN; NERY, 2013, p. 286). Além disso, pretendíamos discutir diretamente a questão da autonomia, da identidade e da interação dos profissionais em uma comunidade de prática entre os tutores e a coordenação. Segundo Daniels (2003, p. 124), "os participantes carregam suas próprias histórias distintas, e o sistema de atividade possui, ele mesmo, múltiplas camadas e filamentos de história gravados em seus artefatos, regras e convenções".

A partir do levantamento bibliográfico internacional realizado e do nosso referencial de análise definimos onze questões estruturadas e abertas que foram respondidas pelos tutores/orientadores ao final do processo de orientação. Considerando a especificidade deste texto e visando respeitar o limite estabelecido para esta publicação, selecionamos cinco questões para discussão. Elas abordavam os seguintes aspectos: expectativas sobre o trabalho de orientação; diferenças entre orientação presencial e no ensino on-line; autonomia diante das orientações da coordenação; uso e avaliação do ambiente do EC-TCC considerando ferramentas e seu estilo de orientação; uso e avaliação do EC-EDITCC; avaliação da experiência de orientação.

Para a realização da pesquisa, antes do início do curso de especialização, todos os cursistas e tutores foram esclarecidos sobre a possibilidade de suas produções serem utilizadas para fins de pesquisa, o que foi assentado em um termo de consentimento livre e esclarecido.

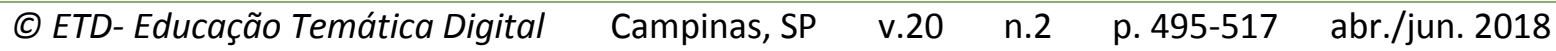




\section{RESULTADOS E DISCUSSÕES DA CARACTERIZAÇÃO DA ATIVIDADE DE ORIENTAÇÃO}

Passamos agora a apresentação e discussão das respostas obtidas junto a dezenove tutores quanto à sua experiência de orientação no EC-FEUSP-Redefor. Observamos que não seria possível discutir as respostas dos tutores-orientadores a partir dos temas das questões, apresentados anteriormente, pois identificamos uma dispersão de temáticas nas diferentes respostas. Assim, a análise das respostas se deu através de um processo de agrupamento, no qual as temáticas foram transformadas em categorias de análise que orientassem nossa discussão e interpretação dos dados de acordo com o modelo de sistemas de atividades. Do conjunto das respostas selecionamos para exemplificação e análise alguns trechos extraídos dos tutores-orientadores - cujos nomes foram preservados e grafias respeitadas - para ilustrar os principais resultados da pesquisa. Destacamos que as respostas obtidas no conjunto dos questionários foram bastante semelhantes, permitindo facilmente a seleção de trechos representativos de diferentes tutores. Estruturamos esta seção de acordo com nossas categorias de análise que serão discutidas a seguir: organização do trabalho pela coordenação e ferramentas da educação on-line; comparação entre orientação presencial e on-line; expectativas e formação do orientador; autonomia, regras de funcionamento e comunidade. Organização do trabalho pela coordenação e ferramentas do ensino on-line.

Essa primeira categoria de análise remete a uma das principais características da teoria da atividade para Engeström (1999a, p. 378): ela é "contextual e orientada para a compreensão de práticas locais historicamente específicas, seus objetos, artefatos mediadores e organização social". Ele ainda a caracteriza como baseada em uma perspectiva dialética que procura interpretar e provocar mudanças qualitativas nas práticas humanas ao longo do tempo.

Como já apresentado, os tutores-orientadores trabalharam com grupos de 10 cursistas, os quais eles já haviam orientado as atividades em disciplinas desde o início do curso. Essa organização foi muito bem vista pelos tutores que ressaltaram o fato de já conhecerem os alunos e suas potencialidades como um fator positivo para a orientação:

"Foi muito produtivo, já que os grupos se constituíram predominantemente dos cursistas que já conhecíamos, logo, eu tinha mais liberdade para me comunicar, seja positivamente ou para chamar a atenção" (Tutor $A)^{7}$.

\footnotetext{
${ }^{7}$ Destaques no texto do tutor seguirão em sublinhado.
}

$\begin{array}{llllll}\text { (C) ETD-Educação Temática Digital } & \text { Campinas, SP } & \text { v.20 } & \text { n.2 } & \text { p. 495-517 } & \text { abr./jun. } 2018\end{array}$


Por outro lado, o pouco tempo para a produção dos TCC foi criticado pela Tutora I e pelo Tutor C. "Achei que o processo ocorreu de forma muito rápida. Acho que os cursistas deveriam ter um tempo a mais e claro os orientadores também", segundo a Tutora I. Como relatado pelo Tutor $\mathrm{C}$, apesar do pouco tempo, de modo geral a proposta de pesquisa apresentada pela coordenação foi muito bem recebida pelos tutores. Destacamos aqui algumas falas sobre o aspecto formativo da proposta quanto à formação dos professores de ciências e cursistas do EC-FEUSP-Redefor, ao mesmo tempo em que isso se configura em um desafio:

“[...] se baseia num processo de pesquisa da própria prática. Isso é muito interessante, especialmente para um curso de especialização, mas gera uma dificuldade maior de compreensão pelos cursistas, não acostumados a esse modelo de TCC" (Tutora E).

"Como a proposta de pesquisa era em relação à aplicação de uma SD pelos alunos, também já previa a dificuldade de os mesmos conseguirem separar o professor e o pesquisador no momento da escrita do trabalho" (Tutora P).

A fala da Tutora P remete ao quarto nível de contradição dos sistemas de atividades, indicando um vínculo estreito entre a atividade de pesquisa e a atividade docente. Segundo Engeström (2015, p. 22-3), "os profissionais desempenham a tarefa de encarar e resolver contradições do seu sistema de atividades, assim que elas são identificadas e intensificadas ao longo da jornada através da zona de desenvolvimento proximal". Nesse caso, o indivíduo deve assumir dois papéis diferentes (professor e pesquisador) em um mesmo contexto de trabalho, já que faz a análise da SD que ele produziu e aplicou em sala de aula. Ao tutor, como par mais avançado, compete oferecer ferramentas para a identificação e resolução das contradições em um processo contínuo de negociação.

As ferramentas disponibilizadas para o trabalho de orientação, considerando os espaços de troca e discussão com a coordenação e com os cursistas e entendidas, no contexto da teoria da atividade, como artefatos mediadores, se mostraram muito eficazes para os tutores. No entanto, houve um consenso de que o fórum de discussão foi pouco usado pelos cursistas, embora alguns destaquem que esse espaço foi rico, e que a ferramenta de diálogo foi a mais usada na orientação dos alunos. Ressaltamos que o SA Orientação é entendido a partir do sujeito tutor e do cursista, como mostra a Figura 1, assim, a dificuldade de mobilização de parte da comunidade para o uso da ferramenta não diminui o reconhecimento de sua importância e papel por parte do orientador.

$\begin{array}{llllll}\text { (C) ETD-Educação Temática Digital } & \text { Campinas, SP } & \text { v.20 } & \text { n.2 } & \text { p. 495-517 } & \text { abr./jun. } 2018\end{array}$ 
“[...] todas as ferramentas foram importantes, mas acho que a ferramenta diálogo foi a mais importante, pois permitia uma comunicação direta entre orientando e orientador e esta ficava registrada e permitia o envio de arquivos" (Tutor S).

"Achei que houve um excelente aproveitamento das ferramentas disponíveis no AVA para o desenvolvimento do TCC. [...] O fórum de discussão foi pouco utilizado pelo grupo. Os cursistas conversaram pouco ao longo do desenvolvimento do trabalho, mas também aproveitava para reforçar algumas orientações gerais. 0 diálogo foi a principal ferramenta de orientação" (Tutor L).

O Tutor C e as Tutoras D e J sugeriram a adoção de ferramentas síncronas de comunicação, pois acreditam que elas facilitariam o trabalho de orientação, segundo a Tutora J, "pois ela quebraria alguns mal entendidos ou leituras equivocadas que cursistas, por ventura, façam de sua orientação". A única sugestão diferente dessa veio da Tutora R, para ela poderíamos incentivar os alunos a usarem o "BLOG individual de forma opcional, para que os alunos façam lá um diário, relatando o processo".

Observamos também algumas críticas das Tutoras $P$, I e do Tutor $M$ quanto às orientações gerais para a pesquisa fornecidas pela coordenação. Para a Tutora I "o único empecilho é muitas informações chegavam de última hora". Por todos estarem envolvidos em uma primeira experiência de formação neste formato e pela organização e coordenação do curso agrupar diversas instâncias hierárquicas (Secretaria da Educação, Universidades, Coordenação do Curso) alguns prazos foram alterados e alguns documentos dependiam da aprovação de todos os envolvidos para serem disponibilizados, o que criava uma grande pressão sobre o cronograma de produção do TCC.

\section{Comparação entre orientação presencial e on-line}

Apesar de a maioria dos tutores terem vivenciado sua primeira experiência como orientadores, eles estabeleceram comparações nas modalidades de orientação (presencial e on-line) com base em sua experiência como orientandos. A recuperação das vivências anteriores ao início do trabalho de orientação, bem como a reflexão sobre esse processo vem sendo sugerida na literatura internacional como um dos principais meios de promover a formação do orientador (MANATHUNGA et al., 2010; SWEITZER, 2009; MCCORMACK; PAMPHILON, 2004). Nesse mesmo sentido, entendemos que, apesar da mesma experiência ser vivida em papéis diferentes, a vivência como orientando contribui para a formação do orientador, assim como a vivência do aluno reconhecidamente compõe a formação ambiental do professor e, portanto, deve ser considerada nesse processo (CARVALHO; GIL-PÉREZ, 2006).

(C) ETD-Educação Temática Digital Campinas, SP $\quad$ v.20 $\quad$ n.2 $\quad$ p. $495-517 \quad$ abr./jun. 2018 
Nesse aspecto, mesmo que ocupando diferentes papéis, os tutores compararam a orientação presencial e on-line por meio de posicionamentos contraditórios reconhecendo diferenças, desafios, vantagens e desvantagens, associadas ao formato on-line, bem como igualdade entre as duas modalidades. As Tutoras que identificaram semelhanças se apoiaram em demandas que elas julgaram comuns a ambos formatos: estar "sempre disponível aos meus cursistas" (Tutora J) e obrigatoriamente usar ferramentas tecnológicas (Tutora R). Para a Tutora M o engajamento dos cursistas tornou "o trabalho com orientação na EaD mais prazeroso do que no presencial". Porém, a maioria das postagens encontrou na escrita e na comunicação a principal desvantagem e vantagem do ensino on-line. Esse dado é coerente com a literatura internacional que situa na escrita um dos principais desafios da orientação, chegando a propor a existência de orientadores específicos para esse aspecto (BUTTERY et al., 2005).

"o processo presencial me pareceu mais fácil de ser conduzido do que na EAD. A falta de oportunidade de trocas mais intensas, com discussões para orientadas para a pesquisa torna o trabalho de orientação mais difuso." (Tutora W)

"As facilidades referem-se ao registro de todas as discussões, as quais podem ser resgatadas por orientador e orientandos a qualquer momento." (Tutor R)

"Os TCCs finais tiveram uma qualidade maior do que eu esperava. A meu ver, isso se deve ao fato de que toda a orientação foi por escrito, com produções constantes, por escrito, dos cursistas. Alunos com o mesmo nível mas orientação presencial, na minha experiência, produzem piores textos pois não escrevem com tanta freqüência, já que têm a possibilidade de conversar a respeito de suas idéias". (Tutora S)

Esse mesmo tema foi objeto de discussão no contexto das ferramentas e da formação para a orientação. Para a Tutora $D$, "as ferramentas não foram muito eficazes mas não por um problema nelas, mas sim, por um problema de cultura que impunha esta falta de eficácia: Os cursistas não lêem de forma atenta e interessada o que lhes é escrito". Para a Tutora P, "a relação à distância implica na frieza do texto escrito, portanto temos que ter mais cuidado na forma que escrevemos e apresentar mais detalhes do que queremos dizer, para evitar interpretações errôneas por parte dos alunos." Essa dificuldade nos parece intrínseca a qualquer curso on-line, independente dos objetivos buscados, portanto não é específico do trabalho de orientação. Por outro lado, essa atividade potencializa a importância da escrita na produção de um texto sob supervisão de um orientador, como discutido na pesquisa de Riolfi e Andrade (2009), e nesse caso as ferramentas on-line de comunicação podem ter favorecido a realização da atividade de orientação por razões complementares como os recursos de comentário ou a busca por palavra-chave. As formas de uso das ferramentas on-

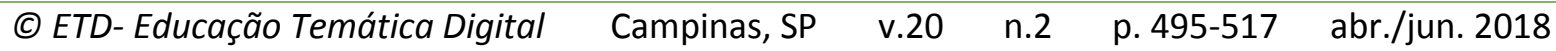


line foram, como se pode observar nos depoimentos dos tutores, determinantes para a orientação, e seu domínio pelos sujeitos desse sistema de atividades foi necessário na mediação de boa parte da produção do objeto do sistema, o TCC.

A ênfase e recorrência dessas considerações nos leva a supor que no ensino on-line a escrita/comunicação é o antigo elemento que colide com o novo elemento de fora (nova tecnologia) e "causa uma contradição secundária agravada", de acordo com o quarto princípio da teoria da atividade para Daniels (2003, p. 124). Nesse caso, a escrita e a comunicação sempre tiveram papel fundamental em qualquer processo de orientação, porém no contexto do ensino on-line esses elementos são ressignificados assumindo novos contornos e produzindo ampliações e reduções no sistema de orientação como o avanço que o registro escrito representa na apropriação da linguagem acadêmica e na possibilidade de recuperação da memória do trabalho, ou a desatenção do cursista durante a leitura de textos on-line. As contradições são, nesse sentido, inerentes às alterações introduzidas pelo uso de ferramentas culturais e os contextos de produção indiciam de forma mais ou menos evidente suas limitações e potencialidades.

\section{Expectativas e formação do orientador}

Como já comentamos, essa foi a primeira experiência como orientadores para muitos dos tutores, assim foram recorrentes comentários como o do Tutor C: "Eu estava empolgado, mas ao mesmo tempo um pouco inseguro, já que esse foi a minha primeira vez que fui orientador". Assim, como na discussão anterior, observamos que as experiências como orientandos nortearam as ações dos tutores, através de um movimento explicitado pela Tutora W: "o principal eixo norteador para o meu trabalho de orientação foi minha experiência como orientanda". Além disso, mesmo no uso das ferramentas observamos a tentativa de reproduzir modelos de organização dos tradicionais grupos de pesquisa:

"Inicialmente houve a tentativa de discutir sobre os TCC's em um grande fórum, de forma semelhante ao que ocorre nos grupos de estudos e pesquisas, contudo, pela variedade de temas e objetos de estudo as orientações foram realizadas em caráter individualizado através de diálogos e mensagens." (Tutor R)

"Minha intenção era promover, no fórum de discussão, uma dinâmica de orientação colaborativa, na qual os cursistas pudessem trocar não só experiências como também ansiedades e incertezas." (Tutora $M$ )

A formação para a orientação parece ter tido efeitos positivos nos tutores, porém a equipe do curso como um todo representou um papel mais importante como suporte da atuação dos orientadores neófitos. Acreditamos que isso seja explicado principalmente pela

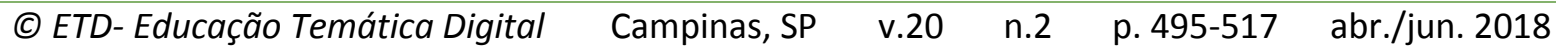


presença constante da coordenação durante todo o processo de orientação, através de espaços abertos para discussão com ela e entre os tutores.

"A formação dada pela REDEFOR, creio ter auxiliado, mas o que mais contribuiu neste aspecto, foram as trocas com outros tutores com os quais mantive contato durante todo o processo." (Tutora W)

"Antes do início do trabalho fiquei bastante ansiosa, pois além de serem muitos alunos, era a minha primeira orientação. Minha confiança era no meu tutor de acompanhamento, que sempre esteve presente e eu sabia que continuaria a me auxiliar no que fosse preciso." (Tutora P)

Apenas a Tutora I concluiu ao final do processo que "orientação a gente só aprende na prática. Ou seja, orientando." Para ela havia uma expectativa de que a formação daria "dicas de forma minuciosa" sobre como orientar, mas hoje ela percebe "que isso não é possível".

Além da equipe, muitos tutores encontraram apoio para a tarefa de orientação no material da disciplina EC-EDITCC. Embora ela tenha sido planejada para os cursistas, eles encontraram nesse material subsídios para o trabalho de orientação, tornando-o mais claro aos orientadores e recomendando textos do curso aos orientandos. Parece-nos que esse elemento foi somado à equipe do curso, se constituindo em mais um elemento dessa comunidade de prática.

"O EDITCC foi uma ferramenta importante no processo de orientação, mas principalmente após o início dos trabalhos. Antes de iniciar o TCC, tive apenas um cursista que estava participando (parcialmente) do EDITCC. Durante as orientações, sempre fiz indicação das aulas no EDITCC. As aulas foram bem produzidas e abordam a produção da pesquisa científica de uma forma interessante e fácil para o cursista." (Tutor L)

"Durante a elaboração do TCC, busquei suporte teórico no EDITCC, que foi uma boa base de materiais a serem passados para os cursistas e muitas vezes, recorri a este espaço como suporte de orientação." (Tutora W)

"Quando estava fazendo leitura dos tccs, várias vezes coloquei trechos nos textos dos cursistas referentes a EDITCC. Indicava também que materiais para leitura complementar que nela estavam presentes. No processo de orientação me auxiliou muito. Quando tinha dúvidas, recorreria a EDITCC." (Tutora I)

Esse cenário remete ao quinto princípio da teoria da atividade segundo Daniels (2003, p. 124), que "proclama a possibilidade de transformações expansivas nos sistemas de

$\begin{array}{llllll}\text { (C) ETD-Educação Temática Digital } & \text { Campinas, SP } & \text { v.20 } & \text { n.2 } & \text { p. 495-517 } & \text { abr./jun. } 2018\end{array}$ 
atividade". Nesse processo "o objeto e o motivo da atividade são reconceituados para abraçar um horizonte mais amplo de possibilidades do que no modo anterior da atividade" (DANIELS, 2003 , p. 125). Assim, o material do EDITCC, produzido inicialmente como uma ferramenta de ensino com fins de auto-estudo, ou seja, uma ferramenta cultural, muda de função dentro do SA Orientação passando a mediar a interação entre orientador e orientando com novas possibilidades de desenho das atividades.

Além disso, percebemos que, de modo geral, o principal aprendizado do processo de orientação se deu quanto à compreensão e ao respeito às particularidades dos níveis de desenvolvimento dos orientandos.

“Aprendi muito, principalmente em respeitar as diversidades particulares e explicar com riqueza de detalhes pensamentos e orientações para facilitar a compreensão (percebi que o detalhamento de ideias ajuda o entendimento). Pretendo em experiências futuras manter a tranquilidade e a velocidade nas respostas (no feedback)." (Tutora $\mathrm{L}$ )

"Saber lidar com minhas dificuldades e com as dos cursistas em processo de orientação, aguardando na medida do possível a elaboração mental de cada um; Identificar as potências e as dificuldades de cada cursista, e, com base nisso, buscar formas de incentivá-los, a fim de que desenvolvessem o máximo possível seus TCC." (Tutor R)

A importância do aspecto particular e artesanal da orientação merece destaque nas discussões sobre o trabalho do orientador. As atividades de formação pautadas nas histórias de vida e relatos de experiência dos sujeitos, indicadas na literatura internacional e incentivadas na comunidade de prática, foram pensadas nesse sentido (MANATHUNGA et al., 2010; SWEITZER, 2009; MCCORMACK; PAMPHILON, 2004).

\section{Autonomia, regras de funcionamento e comunidade}

Enfocamos nesta seção as falas dos tutores que remetem à discussão sobre sua autonomia no processo de orientação. Fica claro que existiam regras de funcionamento nessa comunidade de prática de orientação, mas que a existência dessas regras não tolheu a autonomia individual dos orientadores, servindo pelo contrário como suporte para esse trabalho, apoiando a inserção dos recém-chegados nesta comunidade.

"Eu tenho uma forma muito autônoma de trabalhar. Recorro ao TA [tutor de acompanhamento] ou a coordenação apenas em último caso, ou para relatar alguma experiência. Gosto de tomar decisões e optar por resoluções sempre que

$\begin{array}{llllll}\text { (c) ETD-Educação Temática Digital } & \text { Campinas, SP } & \text { v.20 } & \text { n.2 } & \text { p. } 495-517 & \text { abr./jun. } 2018\end{array}$ 
me julgar capaz para tal. A proposta de TCC do REDEFOR, de certa forma, podou a atuação de tutores e cursistas. Por outro lado, definiu um norte que com certeza facilitou o trabalho de orientação, criando parâmetros de avaliação e comparação de um trabalho com outro. No final, creio que o saldo foi positivo." (Tutora R)

"A autonomia foi parcial, já que os tutores seguiram o modelo proposto pela Redefor [...] De uma maneira geral, seguimos os procedimentos estabelecidos pela Redefor em relação à estrutura, mas acredito que cada um de nós tenha dado o seu 'toque' especial nos encaminhamentos diários desses procedimentos. A autonomia foi, a meu ver, limitada e nem por isso deixou de ser importante e efetiva para que os cursistas finalizassem seus trabalhos." (Tutora M)

"Penso que, enquanto orientadores, tivemos autonomia total para orientar. 0 encontro de formação e as conversas com outros tutores foram fundamentais para uniformizar certos procedimentos não relativos ao nosso trabalho de orientação especificamente, mas sim, procedimentos burocráticos e serviram também para a percepção de que os problemas enfrentados por cada um eram também os mesmos dentro no nosso universo." (Tutora D)

Os depoimentos evidenciam a vivência de uma grande autonomia, porém cerceada pelos limites impostos pelo sistema: as regras da comunidade. Mesmo em falas que ressaltam uma grande autonomia estes limites e a presença das regras e ferramentas da comunidade (apresentadas na Figura 1) aparecem, como no caso da Tutora E: "Eu me senti muito autônoma depois da abertura do ambiente exclusivo para a orientação dos TCCs." Os limites são imposições dos sistemas de atividades, resultado de sua estrutura hierárquica que implicam uma contradição entre o sistema da Coordenação e o sistema de Orientação: ao mesmo tempo em que as regras condicionam a atividade dos orientadores, elas também fornecem condições para o desenvolvimento de sua autonomia.

Assim como o material do EDITCC foi reconfigurado no contexto de orientação, a autonomia atribuída aos orientadores também parece ter levado a efeitos inesperados inicialmente, se configurando em mais um exemplo do quinto princípio da teoria da atividade.

"O que deixei claro, desde o início do trabalho de orientação, era que iria contribuir com o trabalho deles na medida em que dúvidas concretas, projetos sendo elaborados, textos sendo produzidos me fossem encaminhados. Não sugeri tema, deixei que eles escolhessem a SD abordada no TCC, direcionei mas não escrevi os objetivos e questão de pesquisa de cada trabalho. Na medida que eles iam me fazendo as entregas eu ia corrigindo e fazendo as minhas sugestões." (Tutor L)

"Como eu não defini nenhum aspecto na pesquisa dos orientandos, além daqueles previstos no modelo de pesquisa e modelo de TCC, bem como na

$\begin{array}{llllll}\text { (C) ETD-Educação Temática Digital } & \text { Campinas, SP } & \text { v.20 } & \text { n.2 } & \text { p. 495-517 } & \text { abr./jun. } 2018\end{array}$ 
forma/conteúdo do TCC indicados no EC-EDITCC, houve no meu grupo pesquisas com diferentes temas e envolvendo diferentes referencias teóricometodológicos." (Tutora G)

Os depoimentos mostram que da mesma forma que os orientadores vivenciaram uma autonomia circunscrita às regras da comunidade, eles proporcionaram a seus orientandos professores-cursistas estes mesmos limites e autonomia. Esse dado aponta novamente para a importância da formação ambiental no processo de orientação, pois reforça esta tendência de que o orientador de certa forma reproduza neste processo o que vivenciou em outra relação de orientação, neste caso, sua relação com a coordenação do curso. Trata-se de mais uma evidência da articulação entre sistemas de atividades do curso, nesse caso dotada de um propósito específico para desenvolver conjuntamente a orientação e a produção do TCC como sistemas de atividades acoplados.

O sistema de atividades de Coordenação exerceu diferentes funções mediadoras entre os sistemas de produção do curso de especialização, no entanto, a elaboração do TCC foi o objeto que provavelmente trouxe a maior parte de ciclos expansivos acoplados entre os sistemas envolvendo cursistas, tutores e gestores, na medida que cursistas redesenharam sequências didáticas com o objetivo geral de realizar uma pesquisa; tutores desempenharam papel de orientadores de pesquisa; a coordenação estabeleceu as diretrizes de um processo de iniciação à orientação à pesquisa a partir de um documento, o EDITCC. Novas disposições de uso dessa ferramenta cultural em cada um dos sistemas indiciam a ocorrência de aprendizagem expansiva por cada um dos sujeitos das comunidades formadas para o oferecimento do curso de especialização.

\section{CONCLUSÕES}

Neste trabalho, caracterizamos a atuação de tutores de um curso on-line de especialização para professores de ciências como orientadores de TCC, interpretando como os sujeitos se organizam em relação às ferramentas/suportes e comunidade, para a atividade de orientação dos trabalhos de pesquisa. O estudo de características etnográficas foi aqui apresentado em um recorte para analisar respostas a cinco perguntas endereçadas ao tutores logo após concluírem o trabalho de orientação. Esse questionário, bem como a formação dos tutores como orientadores, foi fruto da análise de pesquisas internacionais que nos levou a propor um modelo de orientação coletiva e criar uma comunidade de apoio para o orientador (MCCALLIN; NAYAR, 2012; STEPHENS, 2014). Diante dos resultados obtidos, analisamos aspectos da autonomia, das regras da comunidade, das expectativas e da formação, além de características específicas do trabalho on-line e suas ferramentas.

$\begin{array}{llllll}\text { (c) ETD-Educação Temática Digital } & \text { Campinas, SP } & \text { v.20 } & \text { n.2 } & \text { p. } 495-517 & \text { abr./jun. } 2018\end{array}$ 
Adotamos a Teoria da Atividade (TA) em nossos estudos, pois ela nos auxilia a compreender dois aspectos fundamentais da pesquisa: 1) a formação do orientador dentro de uma comunidade de prática e 2) a reconfiguração que a modalidade ensino on-line traz para o trabalho de orientação. Identificamos vários elementos que apontam para a criação efetiva de uma comunidade de prática que apoiou os tutores nas mais diversas ações, permitindo também a "possibilidade de transformações expansivas nos sistemas de atividade" (DANIELS, 2003, p. 125). Assim, uma disciplina voltada para os alunos foi reconfigurada em objeto de ensino para o trabalho de orientação, sendo esse um dos principais indícios de aprendizagem expansiva verificado entre os tutores. Essa formação nos pareceu coerente com as discussões internacionais mais recentes sobre a "pedagogia da orientação" e o estímulo a modelos de orientação coletiva (MCCALLIN; NAYAR, 2012).

Outro aspecto fundamental observado nesta pesquisa foi o papel da escrita assíncrona na reconfiguração do trabalho de orientação no contexto virtual. É fato que a escrita e a comunicação sempre tiveram papel fundamental em qualquer processo de orientação (ARAÚJO; OLIVEIRA, 2014; BUTTERY et al., 2005; RIOLFI; ANDRADE, 2009), porém no contexto do ensino on-line elas são ressignificadas e assumem uma dimensão determinante das mudanças qualitativas observadas na organização da atividade de orientação. Fundamentalmente, encontramos nas características on-line da comunicação assíncrona e de suas ferramentas, razões para interpretar as alterações qualitativas implementadas por tutores no sistema de atividades de Orientação.

A escassez de pesquisas sobre a atuação do orientador, sobretudo no contexto do ensino on-line, modalidade que conhece forte expansão no meio acadêmico, reflete a necessidade de abordagem da temática, principalmente no contexto nacional. Acreditamos que nossos resultados são um ponto de partida para esclarecer as determinações das ferramentas de escrita e comunicação, bem como suas disposições de uso sobre a organização da atividade de orientação. Além disso, reforça a relevância da continuidade deste estudo, que está prevista através da análise da totalidade dos dados, com o apoio de softwares de análise textual - necessários diante do volume do trabalho -, bem como de um aprofundamento qualitativo na compreensão dos processos formativos do orientador por meio de um estudo mais amplo e prolongado.

\section{AGRADECIMENTOS}

A toda comunidade envolvida no estudo, principalmente aos tutores. A CAPES e CNPq, pelo fomento à pesquisa.

$\begin{array}{llllll}\text { (c) ETD-Educação Temática Digital } & \text { Campinas, SP } & \text { v.20 } & \text { n.2 } & \text { p. } 495-517 & \text { abr./jun. } 2018\end{array}$ 


\section{REFERÊNCIAS}

ALVES, V. M.; ESPINDOLA, I., C., P.; BIANCHETTI, L. A relação orientador-orientando na pósgraduação strictu sensu no Brasil: a autonomia dos discentes em discussão. Revista Educação em Questão, v. 43, n. 29, p. 135-156, 2012.

ARAÚJO, E.; OLIVEIRA, A. Contornos da escrita/pesquisa/autoria e da orientação de mestrandos e doutorandos no contexto académico atual. In: OLIVEIRA, A.; ARAÚJO,E.; BIANCHETTI, L. Formação do investigador: reflexões em torno da escrita/pesquisa/autoria. UFSC, 2014.

BIANCHETTI, L.; QUARTIERO, E. M. Researchers under pressure: a comparative study of the new forms of producing, advising and transmiting knowledge in Brazil and the European Union. European Educational Resarch Journal, v. 9, n. 4, p. 498-509, 2010.

BUTTERY, Ernest Alan; RICHTER, Ewa Maria; LEAL FILHO, Walter An overview of the elements that influence efficiency in postgraduate supervisory practice arrangements. International Journal of Educational Management, v. 19, n. 1, p. 7-26, 2005.

CARVALHO, Anna Maria Pessoa de; GIL-PÉREZ, Daniel. Formação de professores de ciências. 8. Ed. São Paulo: Cortez, 2006.

DANIELS, Harry. Abordagens atuais da teoria sociocultural e da teoria da atividade. In: DANIELS, Harry. (Ed.). Vygotsky e a pedagogia. São Paulo: Edições Loyola, 2003. Cap. 3, p.93125.

ENGESTRÖM, Yrjö. Learning by expanding. 2nd ed. New York: Cambridge Univ. Press, 2015.

. The future of activity theory. In: Sannino et al (org.). Learning and expanding with activity theory. New York: Cambridge Univ. Press, 2009.

Activity theory and individual and social transformation. In: Engeström et al. (org.) Perspectives on activity theory. New York: Cambridge Univ. Press, 1999.

.; MIETTINEN, Reijo; PUNAMÄKI, Raija-Leena (org.). Perspectives on activity theory. New York: Cambridge Univ. Press, 1999.

GIORDAN, Marcelo. Computadores e linguagens nas aulas de ciências. Ijuí: Ed da UNIJUÍ, 2008.

GIORDAN, Marcelo; NERY, Belmayr Knopki. Fundamentos da Teoria dos Sistemas de Atividades oara organizar e interpretar programas de formação continuada de professores em ambientes virtuais de aprendizagem. In: CARVALHO, A. M. P. (Org.) Formação de Professores: múltiplos olhares. São Paulo: Editora Sarandi, 2013. 
GIORDAN, Marcelo; GUIMARAES, Yara A. F.; MASSI, Luciana. Uma análise das abordagens investigativas sobre sequências didáticas: tendências no ensino de ciências. In: VIII Encontro Nacional de Pesquisa em Educação em Ciências e I Congresso Iberoamericano de Investigación en Enseñanza de las Ciencias, 2011, Campinas. Atas..., 2011. p. 1-13.

LEDER, Gilah C. Higher degree research supervision: a question of balance. Australian Universities' Review, v. 2, p. 5-8, 1995.

MANATHUNGA, Catherine; PESETA, Tai; MCCORMACK, Coralie. Supervisor development through creative approaches to writing. International Journal for Academic Development, $v$. 15, n. 1, p. 33-46, 2010.

MASSI, Luciana; GIORDAN, Marcelo. Introdução à pesquisa com sequências didáticas na formação continuada online de professores de ciências. Revista Ensaio, v.16, n.3, p. 75-93, 2014.

MCCALLIN, Antoinette.; NAYAR, Shoba. Postgraduate research supervision: a critical review of current practice. Teaching in Higher Education, v. 17, n. 1, p. 63-74, 2012.

MCCORMACK, Coralie. Stories Return Personal Narrative Ways of Knowing to the Professional Development of Doctoral Supervisors. Studies in Continuing Education, v. 31, n. 2, p.141-156, 2009.

RAUSCH, R. B.; SADALLA, A. M. F. A. Promoção de reflexividade na formação inicial docente: o papel do orientador de pesquisa. Educação Temática Digital, v.9, n.2, p. 170-188, 2008.

RIOLFI, Claudia Rosa; ANDRADE, Emary. Ensinar a escrever o texto acadêmico: as múltiplas funções do orientador. Trabalhos em Linguística Aplicada, Campinas, v. 48, n. 1, jun. 2009.

SANNINO, Annalisa; DANIELS, Harry; GUTIÉRREZ, Kris D. Learning and expanding with activity theory. New York: Cambridge Univ. Press, 2009.

SWEITZER, Vicky Baker. Towards a Theory of Doctoral Student Professional Identity Development: A Developmental Networks Approach. The Journal of Higher Education, v. 80, n. 1, p. 1-33, 2009.

ZHAO, Chun-Mei; GOLDE, Chris M.; MCCORMICK, Alexander C. More than a signature: how advisor choice and advisor behavior affect doctoral student satisfaction. In: Conference of American Educational Research Association, 2005, Montréal. Book of Abstracts..., 2005.

STEPHENS, Simon. The supervised as the supervisor, Education + Training, v. 56, n. 6, p. 537550, 2014.

\footnotetext{
' Revisão gramatical do texto sob a responsabilidade dos autores
}

$\begin{array}{llllll}\text { (C) ETD-Educação Temática Digital } & \text { Campinas, SP } & \text { v.20 } & \text { n.2 } & \text { p. 495-517 } & \text { abr./jun. } 2018\end{array}$ 